\title{
Inseticidas nas sementes e a entomotoxina cry 1 ac protegem a soja contra a lagarta-do-velho-mundo'
}

\author{
Crislaine Sartori Suzana ${ }^{1}$, Karoline Maria Melara ${ }^{2}$, José Roberto Salvadori ${ }^{3}$ \\ ${ }^{1}$ Universidade de Passo Fundo - UFP, Passo Fundo, RS. Doutora em Agronomia. ${ }^{2}$ Engenheira Agrônoma pela \\ Universidade de Passo Fundo - UFP, Passo Fundo, RS. ${ }^{3}$ Universidade de Passo Fundo - UFP e Embrapa. \\ Doutor em Entomologia. E-mail: ssuzana@upf.br; crislaine agronomia@hotmail.com
}

\begin{abstract}
Resumo
A lagarta Helicoverpa armigera ocorre desde a emergência das plantas até a fase reprodutiva da cultura da soja, podendo causar perdas expressivas. Como praga inicial, podem ser encontradas tanto lagartas neonatas como lagartas mais desenvolvidas, estas últimas provenientes da cultura anterior. $\mathrm{O}$ uso de cultivares Bt e de inseticidas em tratamento de sementes são alternativas para manejo da praga no início do desenvolvimento da soja, porém existem dúvidas sobre a eficácia destes métodos de controle. Dessa forma, objetivou-se avaliar o efeito protetivo de inseticidas aplicados às sementes e da proteína Cry 1Ac, em relação ao ataque da lagarta $H$. armigera, como praga inicial em plantas de soja. Experimentos foram conduzidos em laboratório, em delineamento inteiramente casualizado, com seis tratamentos: quatro inseticidas aplicados às sementes e testemunha (sem inseticida), em soja cultivar convencional (BMX Alvo), e a proteína Cry 1 Ac em soja cultivar Bt (DM 5958 IPRO), sem inseticida. Os resultados comprovam que, em condições de laboratório, os inseticidas ciantraniliprole (60 g i.a./100 kg de sementes) e clorantraniliprole (62,5 g i.a./100 kg de sementes) protegem a soja em relação às injúrias das lagartas de H. armigera de 3--4을 ínstares, em cotilédones e folhas unifolioladas e trifolioladas, aos 5 dias após a emergência das plantas. A proteína Cry $1 \mathrm{Ac}$ protege as plantas de soja desse tipo de injúria causado tanto por lagartas de 3-4으 e como 5o-60 ínstares, aos 5 e 10 dias após a emergência.
\end{abstract}

Palavras-chave: controle de pragas; diamidas antranílicas; Helicoverpa armigera; SOJA BT.

\section{Insecticides in seeds and entomotoxin cry 1 ac protect soybeans against the old-world caterpillar}

\begin{abstract}
The Helicoverpa armigera caterpillar occurs from the emergence of the plants to the reproductive stage of the soybean crop, which can cause significant losses. As an initial pest, both neonate and more developed caterpillars can be found, the latter from the previous crop.The use of Bt cultivars and insecticides in seed treatment are options to pest management at the beginning of soybean development, but there are doubts about the efficacy of these control methods. Thus, the objective was to evaluate the protective effect of insecticides applied to seeds and Cry $1 \mathrm{Ac}$ protein, in relation to the attack of the $H$. armigera caterpillar, as an initial pest in soybean plants.

Experiments were conducted in the laboratory, using a completely randomized design, with six treatments: four insecticides related to seeds and control (without insecticide), in conventional cultivar soybeans (Target BMX), and the Cry 1Ac protein in soybeans cultivate Bt (DM 5958 IPRO), without insecticide. Our results confirm that under laboratory conditions the insecticides cyantraniliprole (60 g ai / $100 \mathrm{~kg}$ of seeds) and chlorantraniliprole (62.5 g ai / $100 \mathrm{~kg}$ of seeds) protect the soybean against the injuries of $\mathrm{H}$. armigera 3o-4o ínstars, in cotyledons and unifoliolate and trifoliolate leaves, at 5 days after the emergence of the plants. The protein Cry $1 \mathrm{Ac}$ protects the soybean plants from this type of injury caused by both $3^{\text {rd }}-4^{\text {th }}$ and $5^{\text {th }}-6^{\text {th }}$ ínstars caterpillars, at 5 and 10 days after emergence.
\end{abstract}

Keywords: anthranilic diamides; Helicoverpa armigera; pest control; soybean bt. 


\section{Introdução}

A "lagarta-do-velho-mundo", Helicoverpa armigera (Lep.: Noctuidae: Heliothinae), foi constatada no Brasil e em outros países da América Latina a partir de 2013 (CZEPAK et al., 2013; MURÚA et al., 2014). No Brasil, tem causado danos expressivos não só em lavouras de soja em todo o país, mas também de algodão, na região do cerrado (CZEPAK et al., 2013). Inicialmente, a ansiedade e a falta de conhecimentos levaram os produtores a adotar estratégias de manejo errôneas, até mesmo com aplicações desnecessárias de inseticidas (POMARI-FERNANDES et al., 2015).

Atualmente, o controle de $\mathrm{H}$. armigera tem sido realizado quase que exclusivamente com o uso de inseticidas em pulverização. Devido à ocorrência na cultura da soja desde a emergência das plântulas quando, além de lagartas pequenas provenientes de posturas recentes, lagartas grandes remanescentes da cultura anterior já podem estar presentes na área, o tratamento de semente pode ser uma alternativa para controle (SALVADORI et al., 2013). A adoção de cultivares de soja geneticamente modificadas que expressam a proteína Cry 1 Ac de Bacillus thutingiensis, que confere resistência a certas espécies de lepidópteros, e o uso de inseticidas eficientes, mas com baixo impacto ambiental e seletivos para insetos benéficos, como é o caso do tratamento de sementes, configuram-se como opções para o manejo integrado dessa praga (POMARI-FERNANDES et al., 2015).

O potencial do tratamento de sementes com produtos comerciais à base de clorantraniliprole e ciantraniliprole, do grupo das diamidas antranílicas, recentemente lançados no mercado, e da proteína Cry1AC em cultivares Bt para controle de lagartas neonatas de $H$. armigera já foi constatado em soja (DOURADO et al., 2016; SUZANA et al., 2017). Todavia, não está bem estabelecida a eficiência destes inseticidas e de outros, principalmente de fipronil e tiodicarbe+imidacloprido, que representam grande parte do mercado brasileiro de tratamento de sementes de soja, quando se trata de lagartas mais desenvolvidas atacando a soja, como praga inicial. Outra indagação existente é sobre a eficiência do tratamento de sementes com inseticidas em comparação à entomotoxina Cry 1Ac.

Neste trabalho, objetivou-se avaliar o efeito protetivo de inseticidas aplicados às sementes (cultivar convencional) e da proteína Cry $1 \mathrm{Ac}$ (cultivar Bt), em relação ao ataque da lagarta $H$. armigera, como praga inicial em plantas de soja.

\section{Material e métodos}

Dois experimentos, um com lagartas de tamanho médio ( 1 a $1,5 \mathrm{~cm}$ de comprimento - 3ㅇ4 o ínstares) e outro com lagartas grandes ( 3 a 3,5 $\mathrm{cm}$ de comprimento - 50-6ㅇ ínstares), foram conduzidos em laboratório ( $25 \pm 2 \stackrel{\circ}{ } \mathrm{C}$, umidade relativa de $60 \pm 10 \%$ e fotofase $12 \mathrm{~h}$ ), durante o ano de 2014. Foram utilizadas lagartas provenientes da criação mantida em dieta artificial (GREENE et al., 1976).

A soja foi cultivada em cada de vegetação, em vasos com capacidade para 8 litros de solo, mantidos em bandejas, nas quais foi fornecida a água para as plantas. Todas as sementes foram tratadas com os fungicidas carbendazim+tiram (Derosal Plus, $200 \mathrm{ml} / 100 \mathrm{~kg}$ semente).

Em delineamento inteiramente casualizado avaliou-se 6 tratamentos: 4 inseticidas aplicados às sementes e testemunha (sem inseticida), em soja cultivar convencional (BMX Alvo), e a proteína Cry $1 \mathrm{Ac}$ de Bacillus thuringiensis, em soja cultivar Bt (DM 5958 IPRO), sem inseticida. Os inseticidas avaliados (ingrediente ativo, produto comercial e dose em i.a/100 kg de sementes), foram: a) fipronil (Belure, $50 \mathrm{~mL}$ ), b) imidacloprido+tiodicarbe (Cropstar, $75+225 \mathrm{~mL}$ ), c) clorantraniliprole (Dermacor ${ }^{\circ}, 62,5 \mathrm{~mL}$ ), e d) ciantraniliprole (Fortenza FS $600^{\circ}, 60 \mathrm{~mL}$ ).

Os tratamentos foram avaliados a partir da infestação direta nos vasos, colocando-se as lagartas sobre as plantas, as quais foram protegidas por gaiolas de tecido de malha fina (voal). Para lagartas de tamanho médio (3ㅇ-4은 ínstares), a unidade experimental foi um vaso com 2 plantas infestadas com 10 lagartas, com 4 repetições. Para as grandes (50-60 ínstares), foi um vaso com 5 plantas infestadas com 2 lagartas, com 4 repetições. As infestações foram realizadas aos 5 e 10 dias após a emergência das plantas, correspondendo aos estádios V1 (uma folha trifoliada aberta) e V2 (duas folhas trifoliadas abertas) (HANWAY; THOMPSON, 1967), respectivamente.

Três dias após cada infestação, o efeito de proteção dos tratamentos foi avaliado quanto a injúrias nos cotilédones e nas folhas unifolioladas e trifolioladas, estimando-se o consumo das lagartas pela sobreposição das porções restantes 
sobre papel milimetrado e em comparação aos mesmos órgãos de plantas do mesmo estádio de desenvolvimento, não infestadas. Também foi registrado o número de lagartas vivas e mortas, porém esses dados não foram utilizados por terem sido mascarados pelo canibalismo e pela perda de lagartas no solo. Ao final das observações, foi determinada a massa seca das plantas remanescentes. Os dados de consumo e massa seca foram submetidos à análise de variância e as médias comparadas pelo teste de Tukey $(p \leq 0,05)$.

\section{Resultados e discussão}

Para as lagartas de tamanho médio (3-.4으 ínstares) (Figura 1), aos 5 dias após a emergência das plantas, o consumo de cotilédones na cultivar Bt e na cultivar convencional cujas sementes foram tratadas com clorantraniliprole e ciantraniliprole foi inferior ao da testemunha (cultivar convencional, sem inseticida). A entomotoxina Cry $1 \mathrm{Ac}$ e esses dois inseticidas não diferiram entre si e proporcionaram um elevado grau de proteção às plantas, com uma redução média no consumo de $93,5 \%$, em relação à testemunha. Os tratamentos de sementes com fipronil e imidacloprido+tiodicarbe igualaram-se à testemunha, portanto não evitaram as injúrias das lagartas nos cotilédones. Os resultados aos 10 dias após a emergência das plantas confirmaram o melhor desempenho registrado na primeira avaliação da proteína Cry $1 \mathrm{Ac}$ e dos inseticidas clorantraniliprole e ciantraniliprole, que ofereceram uma proteção média de $94,7 \%$ aos cotilédones. Fipronil apresentou um acréscimo de proteção em relação a ele próprio na primeira avaliação, porém não diferiu da testemunha.

Quanto ao consumo de folhas pelas lagartas de tamanho médio (Figura 1), tanto aos 5 como aos 10 dias após a emergência, a proteína Cry 1Ac, na cultivar Bt, e os inseticidas clorantraniliprole e ciantraniliprole, na cultivar convencional, protegeram as plantas em relação à testemunha. Porém, a proteção média $(87,6 \%)$ proporcionada às folhas por esses tratamentos foi inferior à observada em cotilédones. Fipronil e imidacloprido+tiodicarbe igualaram-se à testemunha, com desempenho inferior à proteína Cry $1 \mathrm{Ac}$ e aos inseticidas clorantraniliprole e ciantraniliprole. Para esse tamanho de lagarta, o efeito protetor da proteína Cry $1 \mathrm{Ac}$ e dos inseticidas clorantraniliprole e ciantraniliprole se mostrou semelhante em cotilédones e em folhas, independentemente do período de tempo transcorrido após a emergência das plantas de soja (5 e 10 dias após).

Para as lagartas grandes (50-60 ínstares) (Figura 2), o consumo de cotilédones aos 5 dias após a emergência das plantas foi inferior na cultivar Bt e na cultivar convencional cujas sementes foram tratadas com os inseticidas ciantraniliprole e imidacloprido+tiodicarbe, com uma redução média de $96,8 \%$. Aos 10 dias após emergência, o consumo de cotilédones em relação à testemunha manteve-se inferior apenas na cultivar Bt $(-96,4 \%)$ e no tratamento com ciantraniliprole (-93,4\%). Nessa segunda avaliação, o tratamento de sementes com imidacloprido+tiodicarbe não diferiu da testemunha, evidenciando perda de efeito nos cotilédones. Por outro lado, o clorantraniliprole igualou-se tanto à cultivar Bt como à testemunha.

O consumo em folhas pelas lagartas maiores (Figura 2), aos 5 dias após a emergência, também foi inferior na cultivar Bt $(-93,8 \%)$ e na cultivar convencional tratada com ciantraniliprole $(-84,3 \%)$, em relação à testemunha. Na segunda avaliação, aos 10 dias após a emergência, a proteção às injúrias foliares manteve-se evidente na cultivar Bt, com redução de $96,6 \%$ no consumo. As diamidas, embora não tenham diferido da cultivar $\mathrm{Bt}$, demonstraram perda no potencial de evitar a alimentação das lagartas maiores, em comparação com os resultados verificados para as lagartas menores. O imidacloprido+tiodicarbe, que na primeira avaliação tinha mostrado uma possibilidade de efeito, igualou-se à testemunha sem inseticida, não confirmando a ação de proteção. $O$ inseticida fipronil confirmou não ter efeito de proteção de cotilédones e de folhas em relação à alimentação das lagartas grandes, em ambas as avaliações, resultado esse já observado em outros trabalhos em tratamento de semente na cultura da soja (SUZANA et al., 2017). 
Figura 1. Consumo de cotilédones e de folhas de soja por lagartas de 3으 40 ínstar de H. armigera aos 5 e 10 dias após a emergência de plantas de cultivar convencional, com e sem (testemunha) inseticidas ${ }^{1}$ nas sementes, e de plantas de cultivar Bt (Cry 1Ac) ( $25 \pm 2$ 우; $60 \pm 10 \%$ UR; $12 \mathrm{~h}$ de fotofase).

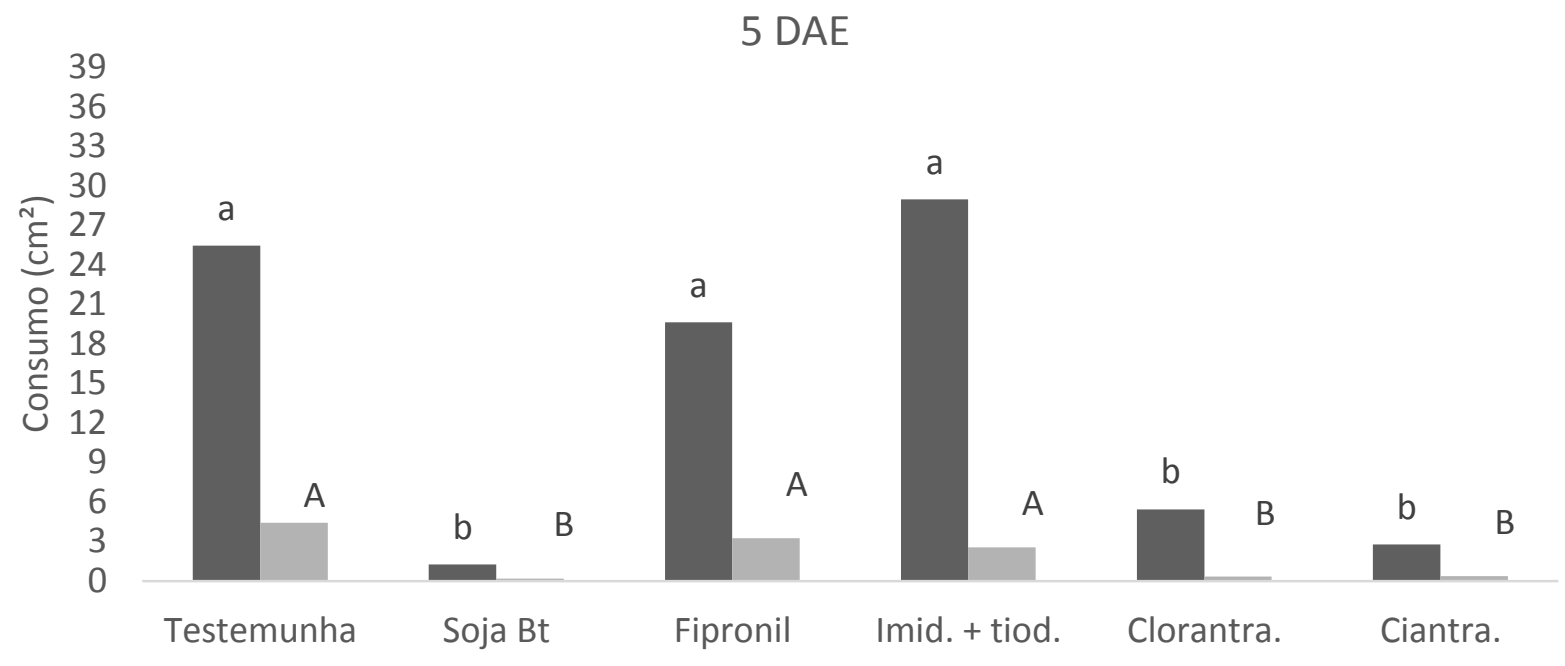

\section{$10 \mathrm{DAE}$}

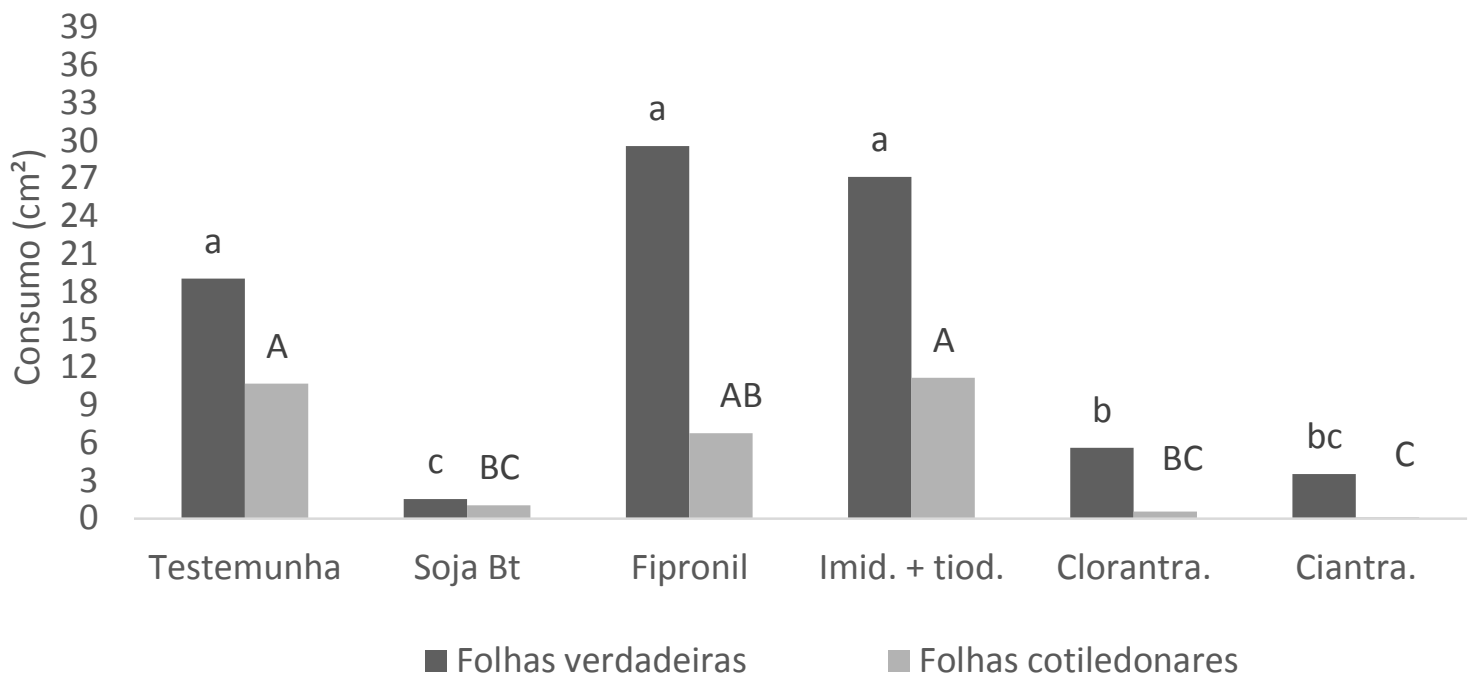

Médias seguidas pela mesma letra (minúsculas em folhas, maiúsculas em cotilédones), não diferem entre si (Tukey, $\mathrm{p} \leq 0,05) .{ }^{1}$ Imid.+tiod.(imidacloprido+tiodicarbe), clorantra. (clorantraniliprole) e ciantra (ciantraniliprole). 
Figura 2. Consumo de cotilédones e de folhas de soja por lagartas de 5- 60 ínstar de H. armigera aos 5 e 10 dias após a emergência de plantas de cultivar convencional, com e sem (testemunha) inseticidas ${ }^{1}$ nas sementes, e de plantas de cultivar Bt (Cry 1Ac) ( $25 \pm 2{ }^{\circ} \mathrm{C} ; 60 \pm 10 \%$ UR; $12 \mathrm{~h}$ de fotofase).

\section{DAE}

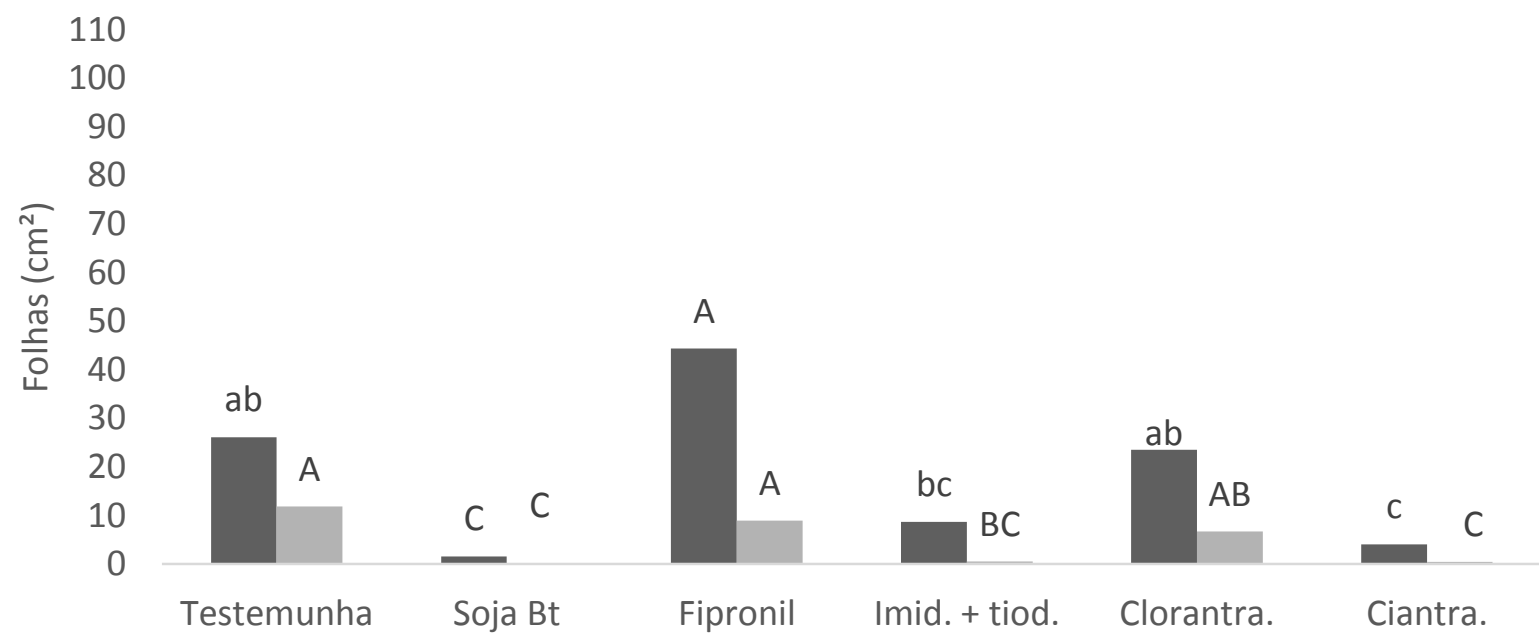

\section{$10 \mathrm{DAE}$}

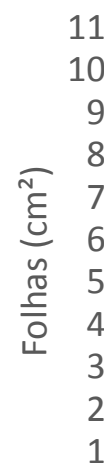

a
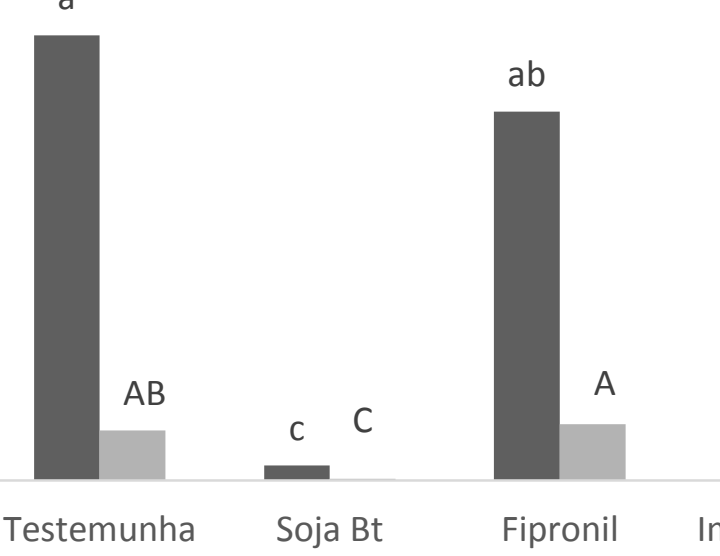

a

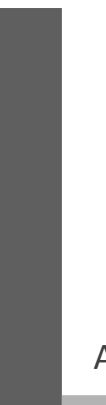

Fipronil

Imid. + tiod.

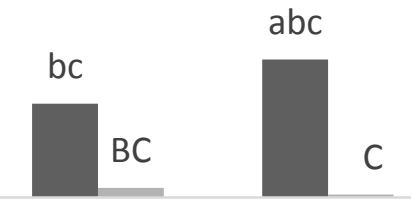

Folhas verdadeiras

Folhas cotiledonares

Médias seguidas pela mesma letra (minúsculas em folhas, maiúsculas em cotilédones), não diferem entre si (Tukey, $\mathrm{p} \leq 0,05)$. ${ }^{1}$ Imid.+tiod.(imidacloprido+tiodicarbe), clorantra. (clorantraniliprole) e ciantra.(ciantraniliprole). ciantra: ciantraniliprole.

Com relação às diamidas e à proteína Cry $1 \mathrm{Ac}$, os resultados são coerentes com os de outros estudos que demonstraram a eficiência do tratamento de sementes de soja com ciantraniliprole e clorantraniliprole para controle de lagartas de 10 ínstar de $H$. armigera, da mesma forma que a proteína Cry 1 Ac para lagartas de 1 ㅇ e de 3 o ínstares (SUZANA et al., 2017). Também são convergentes com a alta sensibilidade relatada para $H$. armigera a proteínas de Bacillus thuringiensis var. kurstaki HD-1 var. kurstaki HD-1 e a diamidas, pulverizadas em plantas de soja (KUSS et al., 2015).

O menor consumo de cotilédones e de folhas por lagartas de 3 -4으 ínstares de $H$. armigera, em ambas as avaliações, e o consumo igual ao da testemunha por lagartas de 50-60 ínstares, especialmente na segunda avaliação, indicam que $\mathrm{o}$ efeito de proteção de ciantraniliprole e de clorantraniliprole depende do tamanho das lagartas e do tempo transcorrido após a emergência das plantas (SUZANA et al., 2017; FILHO et al., 2014). Uma relação positiva entre consumo e a mortalidade das lagartas é 
esperada devido ao mecanismo de ação das diamidas. Agindo nos receptores de rianodina, as diamidas causam a liberação irregular e o esgotamento do estoque de cálcio das células musculares provocando, em consequência, interrupção da alimentação, letargia, paralisia muscular e, finalmente, a morte do inseto (CORDOVA et al., 2006; LAHM et al., 2007; HANNIG et al., 2009).

O efeito de proteção de clorantraniliprole demorou mais para se manifestar em relação a ciantraniliprole, para lagartas de 5-60 ínstares, aos 5 dias após a emergência das plantas. Ciantraniliprole apresenta maior absorção radicular e translocação no tecido foliar que clorantraniliprole, mesmo em situações de baixa umidade do solo.

O consumo de uma menor quantidade de tecido vegetal constatado para as lagartas de 3 ㅇ40 ínstares, tanto nas plantas que expressam a entomotoxina Cry $1 \mathrm{Ac}$ como nas plantas provenientes de sementes tratadas com as diamidas antranílicas foi confirmado por meio da massa seca das porções remanescentes das plantas (dados não apresentados). Os resultados mostram que a proteína Cry $1 \mathrm{Ac}$ é suficiente para reduzir o consumo de tecido vegetal foliar mesmo de lagartas grandes, nas quais o potencial de causar injúrias é maior devido à necessidade de uma maior ingestão para que o efeito da entomotoxina se manifeste (BORTOLOTTO et al., 2014; AZAMBUJA et al., 2015; SUZANA et al., 2017).

Em plantas de soja pequenas, quando as lagartas já estão bem desenvolvidas, apesar da proteção que possam oferecer quanto à injúria das lagartas em cotilédones e folhas unifolioladas e trifolioladas, produtos à base de ciantraniliprole ou clorantraniliprole podem apresentar falhas de controle da praga. Como os referidos ingredientes ativos agem por ingestão, algumas plantas podem ser sacrificadas para que lagartas que, eventualmente, cortam a haste junto ao solo ou um pouco acima, venham morrer. Esta situação foi constatada nesse trabalho e tem sido observada em condições de campo quando a soja é semeada em área previamente infestada com lagartas de H. armigera (SALVADORI et al., 2013).

\section{Conclusões}

Os inseticidas ciantraniliprole (60 g i.a./100 $\mathrm{kg}$ de sementes) e clorantraniliprole $(62,5 \mathrm{~g}$ i.a./100 kg de sementes) protegem a soja em relação às injúrias das lagartas de $H$. armigera de
30-40 ínstares em cotilédones e em folhas unifolioladas e trifolioladasas, aos 5 dias após a emergência das plantas. A proteína Cry $1 \mathrm{Ac}$ (cultivar $\mathrm{Bt}$ ) protege as plantas de soja desse tipo de injúria causado tanto por lagartas de 3-4으 e como de 5--60 ínstares, aos 5 e 10 dias após a emergência.

\section{Referências}

AZAMBUJA, R.; DEGRANDE, P. E.; SANTOS, R. O.; SOUZA, E. P.; GOMES, C. E. C. Effect of Bt Soybean on Larvae of Helicoverpa armigera (Hübner) (Lepidoptera: Noctuidae). Journal of Agricultural $\begin{array}{llll}\text { Science; } & \text { v.7, } & \text { n.8, } & \end{array}$ https://doi.org/10.5539/jas.v7n8p90

BORTOLOTTO, O. C.; BUENO, A. F.; BRAGA, K.; BARBOSA, G. C.; SANZOVO, A. Características biológicas de Heliothis virescens alimentados com Bt -soybean MON $87701 \times$ MON 89788 e sua isolinha convencional. Anais da Academia Brasileira de Ciências, Rio de Janeiro, v. 86, n.2, p. 973-980, 2014.

CZEPAK, C.; ALBERNAZ, K. C.; VIVAN, L. M.; GUIMARÃES, H. O.; CARVALHAIS, T. Primeiro registro de ocorrência de Helicoverpa armigera (Hübner) (Lepidoptera: Noctuidae) no Brasil. Pesquisa Agropecuária Tropical, Goiânia, v. 43, n.1, p.110-113, 2013. http://dx.doi.org/10.1590/S1983$\underline{40632013000100015}$.

CORDOVA, D.; BENNER, E. A.; SACHER, M. D.; RAUH, J. J.; SOPA, J. S.; LAHM, G. P.; SELBY, T. P.; STEVENSON, T. M.; FLEXNER, L.; GUTTERIDGE, S.; RHOADES, D. F.; WU, L.; SMITH, R. M.; TAO, Y. Anthranilic diamides: A new class of insecticides with a novel mode of action, ryanodine receptor activation. Pesticide Biochemistry and Physiology, v.84, p.196-214, 2006. https://doi.org/10.1016/j.pestbp.2005.07.005.

DOURADO, P. M.; BACALHAU, F. B.; AMADO, D.; CARVALHO, R. A.; MARTINELLI, S.; HEAD, P. H.; OMOTO, C. High susceptibility to Cry1Ac and low resistance allele frequency reduce the risk of resistance of Helicoverpa armigera to Bt soybean in Brazil. PLOS ONE, v.11, e0161388, 2016. http://dx.doi.org/10.1371/journal.pone.0161388

FILHO, M. T. L.; RATTES, J. F.; JAKOBY, G. L.; JUNIOR, O. G.; CABRAL, W. C.; VILELA, F. S. Suscetibilidade de lagartas grandes de 
Helicoverpa armigera ao inseticida Dermacor em tratamento de sementes na fase inicial de desenvolvimento da cultura da soja. In: CONGRESSO BRASILEIRO DE ENTOMOLOGIA, 25, 2014, Goiânia. Anais eletrônicos [...]. Goiânia: Embrapa, 2014.

GREENE, G. L.; LEPPLA, N. C.; DICKERSON, W. A. Velvetbean caterpillar: a rearing procedure and artificial diet. Journal of Economic Entomology, $\begin{array}{llll}\text { v.69, } & \text { n.4, p.487-488, } 1976 .\end{array}$ https://doi.org/10.1093/jee/69.4.487

HANNIG, G. T.; ZEIGLER, M.; MARÇON, P. G. Feeding cessation effects of chlorantraniliprole, a new anthranilic diamide insecticide, in comparison with several insecticides in distinct chemical classes and mode -of-action groups. Pest Management Science, v.65, p. 969-974, 2009. https://doi.org/10.1002/ps.1781.

HANWAY, J. J.; THOMPSON, H. E. How a soybean plant develops. Ames: lowa State University, 1967. 20p. (Special Report; 53).

KUSS, C. C.; ROGGIA, R. C. R. K.; BASSO, C. J.; OLIVEIRA, M. C. N.; PIAS, O. H. C.; ROGGIA, S. Controle de Helicoverpa armigera (Lepidoptera: Noctuidae) em soja com inseticidas químicos e biológicos. Pesquisa Agropecuária Brasileira, v.51, n.5, p.527-536, 2016. http://dx.doi.org/10.1590/S0100204X2016000500013.

LAHM, G. P. et al. Rynaxypyr ${ }^{\mathrm{TM}}$ : A new insecticidal anthranilic diamide that acts as a potente and selective ryanodine receptor activator. Bioorganic Medicinal Chemistry Letters, v. 17, p.6274-6279, 2007. https://doi.org/10.1016/j.bmcl.2007.09.012

MURÚA, M. G.; SCALORA, F. S.; NAVARRO, F. R.; CAZADO, L. E.; CASMUZ, A.; VILLAGRÁN, M. E.; LOBOS, E.; GASTAMINZA, G. First record of Helicoverpa armigera (Lepidoptera: Noctuidae) in Argentina. Florida Entomologist Society, Florida, v.97, n.2, p.854-856, 2014. https://doi.org/10.1653/024.097.0279

POMARI-FERNANDES, A.; BUENOS, A. de F.; SOSA-GÓMEZ, D. R. Helicoverpa armigera: current status and future perspectives in Brazil. Current Agricultural Science and Technology, v.
21, p.1-7, 2015. https://doi.org/10.18539/cast.v21i1.4234

SALVADORI, J. R.; PEREIRA, P. R. V. S.; SPECHT, A. Helicoverpa armigera no Sul. Cultivar Grandes Culturas, v. 176, n. 15, p. 22-23, 2013.

SUZANA, C. S.; DALLAGNOL, L. C.; FORTUNA, L. S.; DAMIANI, R.; TESTON, R. SALVADORI, J. R. Potential of antranilic diamides applied in seeds of soybeans with and without Cry1Ac protein for Helicoverpa armigera caterpilar control. African Journal of Agricultural Research, v. 12, n. 17, p. 1477-1482, 2017. 